\title{
Ocorrência de Doenças em Bananeiras no Estado de Alagoas
}

\author{
Flávia Waneska Rodrigues de Andrade ${ }^{1 *}$, Edna Peixoto da Rocha Amorim ${ }^{1}$, Arlinda Pereira Eloy ${ }^{1 * *} \&$ Maria José \\ Rufino $^{2}$
}

${ }^{1}$ Unidade Acadêmica Centro de Ciências Agrárias, UFAL, Campus Delza Gitaí, CEP 57.100-000, Rio Largo-AL. ; ${ }^{2}$ Agência de Defesa Fitossanitária, SEAG-AL,av. Comendador Leão, s/n, CEP 57 0000, Maceió-AL

Autor para correspondência: Edna Peixoto da Rocha Amorim (epra@ fabeal.br)

Data de chegada: 02/01/2008. Aceito para publicação em: 18/12/2008.

\section{RESUMO}

Andrade, F.W.R., Amorim, E. P. R., Eloy, A. P. \& Rufino, M. J. Ocorrência de doenças em bananeiras no Estado de Alagoas. Summa Phytopathologica, v.35, n.4, p.305-309, 2009

O cultivo da banana é uma importante fonte de renda para pequenos e médios produtores no estado de Alagoas. A maioria dos plantios está localizado em região de mata e próximo a costa, com condição apropriada para a ocorrência e desenvolvimento de doenças. Este trabalho teve como objetivo fazer o levantamento das doenças da bananeira que ocorrem em áreas de plantio localizadas no estado de Alagoas. O trabalho foi conduzido durante os anos de 2006 e 2007, por meio de visitas às propriedades e coleta de materiais de plantas infectadas em 60 áreas produtoras de banana, em quatorze municípios do estado de Alagoas. As amostras coletadas foram analisadas em laboratório para identificação dos patógenos associados com as doenças. Neste levantamento muitas doenças causadas por fungos e nematóides foram observadas, tais como: sigatoca amarela (Pseudocercospora musae) (Zimm.) Deighton; mancha de
Deightoniella (Deightoniella torulosa) (Syd.) Ellis e mancha de Cordana (Cordana musae Zimm), que ocorreram em todas as áreas analisadas; mancha de Chloridium (Chloridium musae Stahel), ocorrendo somente em áreas úmidas e associada a outras manchas foliares; mancha de Exosporella, que foi observada somente em Santana do Mundaú; fitonematoses causadas por Rhadophulus similis, Helicotylenchus multicinctus e Pratylenchus sp., detectados apenas em alguns municípios; mal-do-panamá (Fusarium oxysporum f.sp. cubense) encontrado somente em quatro áreas no Sul do Estado e Murcha bacteriana (Ralstonia solanacearum) (Smith) Yabuuchi et al. (raça 2), encontrada em três áreas. Apesar de mal-do-panamá e moko (Ralstonia solanacearum raça 2) terem sido encontradas em baixa incidência, estas doenças ainda são consideradas como principais problemas em plantações de bananeiras no estado de Alagoas.

Palavras-chave adicionais: Musa sp., fungo, nematóide, bactéria

\section{ABSTRACT}

Andrade, F.W.R., Amorim, E. P. R., Eloy, A. P. \& Rufino, M. J.. Occurence of banana diseases in the state of Alagoas. Summa Phytopathologica, v.35, n.4, p.305-309, 2009

Cultivation of banana is an important source of income for small and middle farmers of the state of Alagoas. Most plantations are located in rain forest and nearshore costal areas, with suitable weather conditions for occurrence and development of diseases. The objective of this work was to survey the diseases of banana occurring in production areas of the state of Alagoas. This work was conducted during 2006 and 2007, by means of visits to farms and assessment of infected plant materials, in 60 banana production areas, distributed in fourteen counties of the state of Alagoas. The material collected was analyzed in laboratory for identification of pathogens associated with diseases. In this survey several diseases caused of fungi and nematodes were observed. It was found the diseases: yellow sigatoca (Pseudocercospora musae) (Zimm.) Deighton; Deightoniella spot
(Deightoniella torulosa) (Syd.) Ellis; Cordana spot (Cordana musae Zimm), the three diseases presented in all areas surveyed; Chloridium spot (Chloridium musae Stahel), occurring only in areas with humidity and associated at others leaf spots; the spot Exosporella found only at Santana do Mundau; Phytonematoses causaded by Rhadophulus similis, Helicotylenchus multicinctus and Pratylenchus sp. found only in some counties; panama disease (Fusarium oxysporum f.sp. cubense) found only in four areas in the outh of the state and bacterial wilt (Ralstonia solanacearum) (Smith) Yabuuchi et al. (race 2), found only in three areas. Even though panama disease and moko disease (Ralstonia solanacearum race 2) were found in low incidence, these diseases still are considered major problems in banana plantations in the State Alagoas.

Keywords: Musa sp., fungi, nematode, bacteria

O Brasil é o $2^{\circ}$ produtor mundial de banana, com produção aproximada de 6,6 milhões de toneladas, numa área cultivada de 560 mil hectares (1). A bananicultura possui grande importância econômica e social, sendo cultivada numa extensa região tropical, geralmente por pequenos agricultores. Além disso, é indiscutível o papel da banana na complementação alimentar das populações de baixa renda e, praticamente, toda a produção brasileira destina-se ao mercado interno.

Entre os maiores problemas do cultivo da banana no Brasil, está a falta de variedades comerciais, com porte adequado e resistência às principais pragas e doenças, e o manejo inadequado do sistema soloágua-planta. Além das doenças como o mal-do-panamá, a sigatoca amarela e o moko, que promovem perdas consideráveis, existe ainda a 
sigatoca negra, causada pelo fungo Mycosphaerella fijiensis var. difformis Mulder \& Stover, recentemente introduzida no País e vêm provocando danos expressivos à bananicultura nacional(5). Essa doença tem trazido grande preocupação para produtores e pesquisadores, tendo em vista que as perdas podem chegar a $100 \%$ da produção em que o controle não é realizado (4). Outro efeito imediato é o custo de controle em função da necessidade de aumento do número de aplicações anuais de fungicidas (mil dólares/hectare/ano), cerca de cinco vezes mais comparado ao controle dispensado para a sigatoca amarela (3). Esta doença infecta as folhas da bananeira, causando uma rápida necrose foliar, reduzindo a capacidade fotossintética da planta, podendo causar-lhe a morte, antes mesmo da formação do cacho e dos frutos, e a conseqüente redução da produçãodabananicultura(4).

Das cultivares de bananeira plantada, $97 \%$ são suscetíveis à sigatoca negra. E são elas as de mesa, 'Pacovan', 'Prata-comum', 'Comprida' e 'Maçã'. Os 3\% restantes são cultivares destinadas às indústrias, como 'Nanica', 'Nanicão' e 'Grand Naine' Todas essas são suscetíveis à sigatoca amarela e sigatoca negra (7). A prevenção e o uso de material vegetal resistente tais como: 'Pacovan Ken', 'Mysore', 'Figo' e 'Preciosa' constituem-se nas alternativas com maiores chances de resolver os problemas com maior eficiência e menores danos ambientais (5).

Diante do exposto, o estabelecimento da sigatoca negra nas zonas produtoras de banana de Alagoas, pode levar a uma crise onde todas elas sucumbirão em pequeno espaço de tempo. Gerando uma crise sócioeconômica sem precedente já que o cultivo da bananeira gera quatro empregos diretos/hectare, durante os 12 meses do ano, tornandose imperativa a implementação de ações no sentido de proteger o setor bananeiro alagoano.

O presente diagnóstico fitossanitário da cultura da banana em Alagoas surgiu em atendimento à solicitação da Agência de Defesa Fitossanitária do Estado de Alagoas, preocupada com a ocorrência da sigatoca negra, nos estados do Amazonas, Acre, Rondônia, Mato Grosso, São Paulo e, mais recentemente, em Minas Gerais (4), em virtude da grande possibilidade de se alastrar por todo o País e, em breve, chegar a Alagoas.

Foram realizadas visitas técnicas em 60 propriedades localizadas nos municípios de Igreja Nova, Branquinha, União dos Palmares, Maceió, Penedo, Porto Calvo, Maribondo, São Luiz de Quitunde, Ibateguara, Joaquim Gomes, Colônia de Leopoldina, Santana do Mundaú, São José da Laje e Palmeira dos Índios. Em cada propriedade foram coletadas amostras de plantas infectadas e, nos casos de sintomas de ataque de nematóides, solo da rizosfera. As amostras foram acondicionadas em sacos plásticos e levadas ao Laboratório de Fitopatologia do Centro de Ciências Agrárias da Universidade Federal de Alagoas. A diagnose das doenças já assinaladas (4) foi feita considerando sintomas e sinais, com auxílio de um microscópio estereoscópico e ótico. As fitonematoses foram identificadas pelos sintomas, presenças de nematóides no sistema radicular (endoparasitas) e população de nematóides do solo detectadas pela extração por meio do método de flutuação centrífuga (6). Foram realizados isolamentos e teste de patogenicidade em relação ao mal-do-panamá e moko. Para o mal-do-panamá o fungo foi cultivado em meio batata-dextrose-ágar (BDA) e a inoculação procedida pela imersão das raízes de mudas micropropagadas de bananeira cv. Maçã, previamente feridas, em uma suspensão de inóculo $\left(10^{4}\right.$ conídios. $\left.\mathrm{mL}^{-1}\right)$. No moko, procedeu-se ao teste do copo, isolamento em meio BDA, caracterização morfológica e teste de patogenicidade do isolado, realizado por meio de picada em frutos sadios e injeção de suspensão da bactéria $\left(10^{7} \mathrm{ufc} / \mathrm{mL}\right)$ em rizomas de mudas de bananeira. O tecido foliar das plantas com suspeita de sigatoca negra foram encaminhadas ao Laboratório da EMBRAPA Mandioca e Fruticultura tropical em Cruz das Almas - BA para serem analisadas. A incidência da doença foi avaliada em função do número de diagnósticos nas propriedades visitadas.

A exudação bacteriana foi observada no teste do copo nas amostras das plantas com sintomas do moko. Em meio BDA, a bactéria apresentou colônias de coloração creme, aspecto circular, bordos bem delimitados e brilhantes. A separação de colônias virulentas e avirulentas foi realizada em meio TZC, no qual se observou colônias brancas com centro róseo. Os testes de patogenicidade confirmaram Fusarium oxysporum f. sp. cubense, como agente do mal-do-panamá e Ralstonia solanacearum (Smith) Yabuuchi et al. (raça 2), identificada através de teste com carboitrados, como causadora do moko nos bananais do Estado de Alagoas.

Em Alagoas, a primeira ocorrência de Ralstonia solanacearum se deu no ano de 1987, no Município de Igreja Nova, lotes 774 e 778, situados no Projeto Irrigado do Vale da Boacica, da Companhia de Desenvolvimento do Vale do São Francisco - CODEVASF, conforme Portaria Ministerial n ${ }^{\circ} 829$, de 13/11/88, publicada no Diário Oficial da União de 28/11/88 e SDA n ${ }^{\circ} 385$, de 27/11/87, ambas do Ministério da Agricultura e do Abastecimento. Novo foco surgiu em 2000, segundo informações da ADEAL-AL, no mesmo município e apesar das medidas de erradicação tomadas pela SEAG-AL, ainda hoje novos focos da doença vêm sendo confirmados.

Foram registradas a ocorrência de diversas doenças (Tabela 1, Figura 1A), principalmente causadas por fungos, nos municípios estudados. Em nenhum momento do levantamento, foi diagnosticada a sigatoca negra, doença da bananeira, alvo do estudo e mais temida por técnicos e produtores. A partir dos laudos de diagnóstico emitidos pelo Laboratório de Fitopatologia do CECA/UFAL, técnicos da ADEAL (SEAG-AL) redigiram um relatório que permitiu ao Ministério da Agricultura expedir Portaria, isentando o Estado como livre da sigatoca negra. Dentre as doenças fúngicas, as mais freqüentes foram a sigatoca amarela (Pseudocercospora musae) a mancha de Deightoniella (Deightoniella torulosa) a mancha de Cordana (Cordana musae), todas estas de ocorrência generalizada nos municípios e localidades visitadas e com uma incidência relativamente danosa e a mancha de Chloridium (Chloridium musae) registrada nos municípios de São Luiz de Quitunde, Ibateguara e Palmeira dos Índios. As fitonematoses foram detectadas apenas em alguns municípios: Rhadophulus similis, Igreja Nova, Penedo, Porto Calvo, São Luiz de Quitunde e Santana do Mundaú; Helicotylenchus multicinctus, Igreja nova, Porto Calvo e Ibateguara; Pratylenchus sp., em União dos Palmares, Joaquim Gomes e Palmeira dos Índios; o mal-do-panamá (Fusarium oxysporum f.sp. cubense) encontrado somente em quatro municípios, Igreja Nova, Ibateguara, São José da Laje e Palmeira dos Índios principalmente, em reboleiras, na cultivar comprida, e o moko (Ralstonia solanacearum), em três áreas, Igreja Nova, Penedo e Palmeira dos Índios.

A Figura 1B apresenta a frequêencia de patógenos nos municípios estudados, onde se pode observar que a freqüência acumulada de fitopatógenos foi maior em P. musae (36,55\%), C. musae $(23,11 \%)$, D. torulosa $(14,5 \%)$, F. oxysporum f. sp. cubence $(6,45 \%), R$. similis $(6,45 \%)$ e $R$. solanacearum $(6,45 \%)$.

A presença de importantes patógenos tais como $F$. oxysporum $\mathrm{f}$. sp cubence e $R$. similis, mesmo em freqüência baixa, exigem medidas de controle, tais como utilização de mudas sadias e rotação de cultura, evitando-se o aumento do inóculo e comprometimento da produção. A presença de $R$. solanacearum, também em baixa freqüência, é ainda 
Tabela 1 Doenças detectadas em plantas de bananeiras no Estado de Alagoas

\begin{tabular}{|c|c|c|}
\hline Municípios & Núm. de Prop. & Doença/Patógeno \\
\hline \multirow[t]{5}{*}{ Igreja Nova } & 10 & Mal-do-panamá (Fusarium oxysporum f.sp cubence ) \\
\hline & & Sigatoca amarela (Pseudocercospora musae) \\
\hline & & Moko (Ralstonia solanacearum) \\
\hline & & Manchas foliares (Cordana musae, Deigtoniella torulosa) \\
\hline & & Fitonematoses (Radophulus similis, Helicotylenchus multicinctus) \\
\hline \multirow[t]{2}{*}{ Branquinha } & 3 & Sigatoca amarela (Pseudocercospora mиsae) \\
\hline & & Manchas foliares (Cordana musae, Deigtoniella torulosa) \\
\hline \multirow[t]{3}{*}{ União dos Palmares } & 5 & Sigatoca amarela (Pseudocercospora musae) \\
\hline & & Manchas foliares (Cordana musae, Deigtoniella torulosa) \\
\hline & & Fitonematoses (Pratylenchus sp.). \\
\hline \multirow[t]{3}{*}{ Penedo } & 10 & Sigatoca amarela (Pseudocercospora musae) \\
\hline & & Manchas foliares (Cordana musae, Deigtoniella torulosa) \\
\hline & & Moko (Ralstonia solanacearum)Fitonematoses (Radophulus similis) \\
\hline \multirow[t]{2}{*}{ Maceió } & 1 & Sigatoca amarela (Pseudocercospora musae) \\
\hline & & Manchas foliares (Cordana musae, Deigtoniella torulosa) \\
\hline \multirow[t]{3}{*}{ Porto Calvo } & 6 & Sigatoca amarela (Pseudocercospora mиsae) \\
\hline & & Manchas foliares (Cordana musae, Deigtoniella torulosa) \\
\hline & & Fitonematoses (Radophulus similis, Helicotylenchus multicinctus.) \\
\hline \multirow[t]{2}{*}{ Maribondo } & 2 & Sigatoca amarela (Pseudocercospora mиsae) \\
\hline & & Manchas foliares (Cordana musae, Deigtoniella torulosa) \\
\hline \multirow[t]{3}{*}{ São Luiz do Quitunde } & 2 & Sigatoca amarela (Pseudocercospora mиsae) \\
\hline & & M. foliares (Cordana musae, Deigtoniella torulosa, Chlor. musae) \\
\hline & & Fitonematoses (Radophulus similis) \\
\hline \multirow[t]{4}{*}{ Ibateguara } & 6 & Sigatoca amarela (Pseudocercospora. mиsae) \\
\hline & & Mal-do-panamá (Fusarium oxysporum cubence) \\
\hline & & M. foliares (Cordana musae, Deigtoniella torulosa, Chlor. musae) \\
\hline & & Fitonematoses (Helicontylenchus multicinctus) \\
\hline \multirow[t]{2}{*}{ Santana do Mundaú } & 2 & Sigatoca amarela (Pseudocercospora musae) \\
\hline & & M. foliares (Cordana musae, Deigtoniella torulosa.) \\
\hline \multirow[t]{2}{*}{ Colônia de Leopoldina } & 2 & Sigatoca amarela (Pseudocercospora musae) \\
\hline & & Manchas foliares (Cordana musae, Deigtoniella torulosa.) \\
\hline \multirow[t]{5}{*}{ Palmeira dos Indios } & 6 & Sigatoca amarela (Pseudocercospora musae) \\
\hline & & Mal-do-panamá (Fusarium oxysporum f.sp cubence) \\
\hline & & M. foliares (Cordana musae, Deigtoniella torulosa, Chloridium) \\
\hline & & Moko (Ralstonia solanacearum) \\
\hline & & Fitonematoses (Pratylenchus sp.) \\
\hline \multirow[t]{2}{*}{ Joaquim Gomes } & 3 & Sigatoca amarela (Pseudocercospora musae) \\
\hline & & Manchas foliares (Cordana musae, Deigtoniella torulosa) \\
\hline \multirow[t]{3}{*}{ São José da Lage } & 2 & Mal-do-panamá (Fusarium oxysporum f.sp cubence) \\
\hline & & Sigatoca amarela (Pseudocercospora musae) \\
\hline & & M. foliares (Cordana musae, Deigtoniella torulosa.) \\
\hline
\end{tabular}




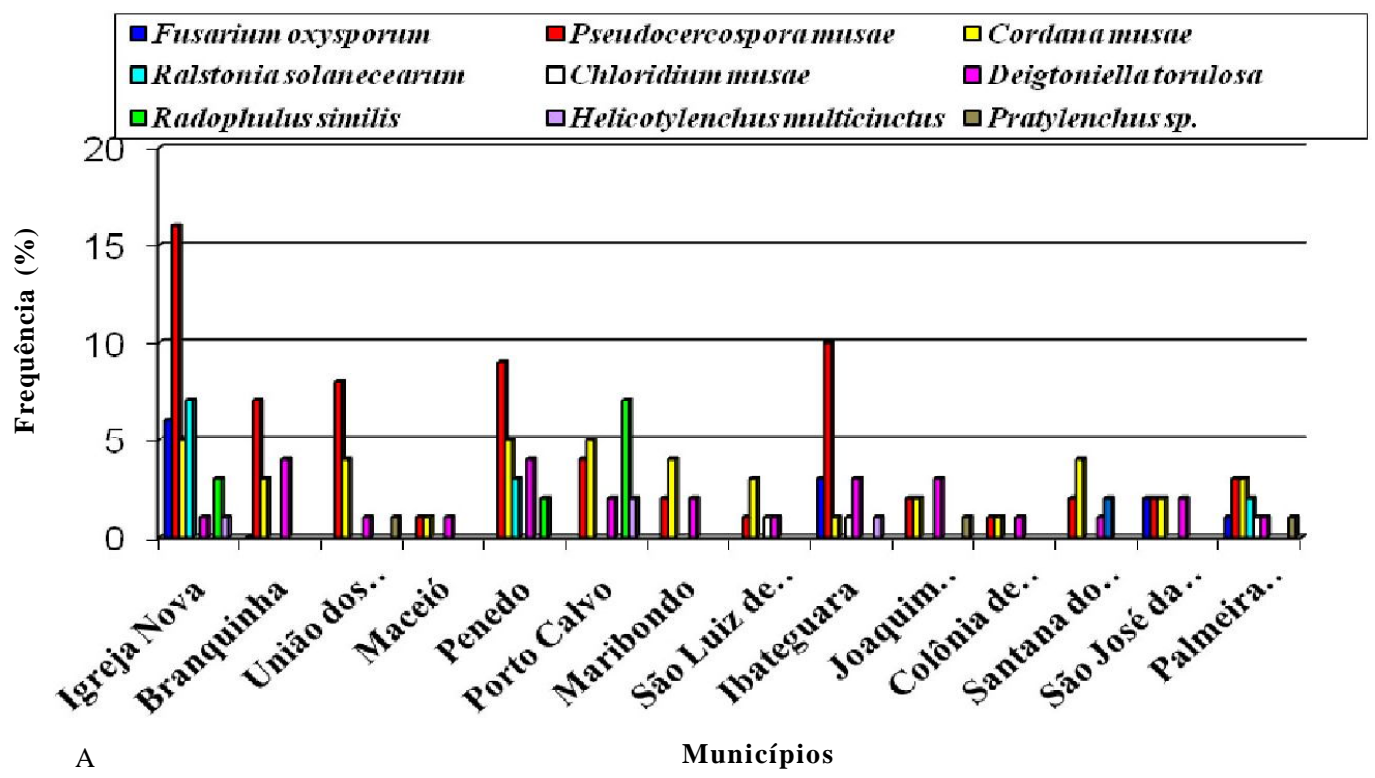

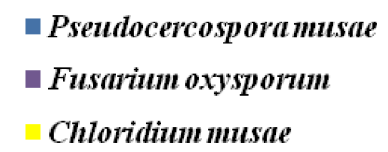

Chloridium musae

\author{
- Cordana musae \\ - Radophulus similis \\ - Helicotilenchusmulticinctus \\ - Deigtoniellatorulosa \\ - Ralstonia solanaceanum \\ Pratylenchussp.
}

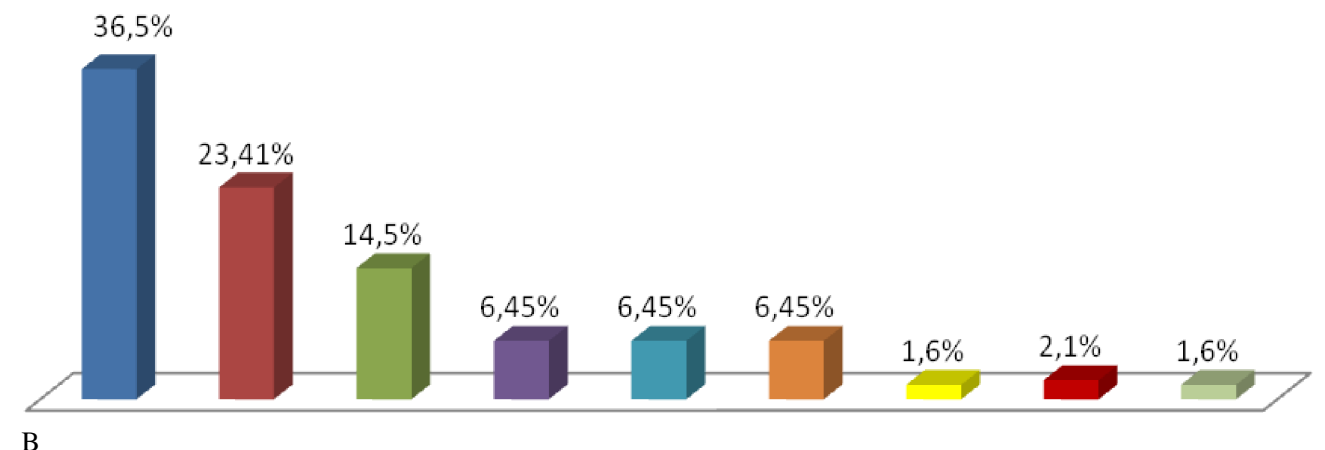

Figura 1. Freqüência de fitopatógenos em plantas de bananeira: A - Distribuição por município; B - Frequiência acumulada dos patógenos no Estado de Alagoas.

mais preocupante, em virtude da gravidade da doença, tendo em vista tratar-se de uma praga quarentenária $\mathrm{A} 2$, o que exige medidas de erradicação imediata dos focos, visando impedir o estabelecimento da doença. A não eliminação de plantios velhos e a presença de plantas de banana atacadas pelas doenças nas estradas de acesso às propriedades contribuem para a manutenção dos patógenos na área (4).

Dentre as manchas foliares, merece atenção a sigatoca amarela $(P$. musae), em virtude da ocorrência generalizada com alta freqüência de plantas infectadas e custos de controle. As demais manchas foliares, mancha de Cordana, mancha de Deightoniella e mancha de Chloridium, são consideradas doenças secundárias da bananeira (4). O fungo Deigtoniella torulosa é relatado como endofítico (2) e causador de manchas em folhas, pecíolos e frutos (8). Entretanto, apesar de ser considerado um patógeno fraco, a ocorrência de folhas rasgadas, em função da ação do vento, é um fator que permite a entrada e estabelecimento de patógenos no tecido foliar da planta. A mancha de Choridium $(1,6 \%)$ ocorreu somente em áreas com sombreamento excessivo e associado a outras manchas foliares.
Os baixos índices de freqüência das fitonematoses, causadas por H. multicinctus $(2,1 \%)$ e Pratylenchus sp. $(1,6 \%)$, não deve ser desprezada, tendo em vista tratar-se de importantes nematóides da bananicultura do Brasil, onde vem causando sérios prejuízos (4).

\section{REFERÊNCIAS BIBLIOGRÁFICAS}

1. Agrianual 2007: Anuário da Agricultura Brasileira. São Paulo: Instituto FNP, 2007. p. 194-2004.

2. Cao, L.X.; You, J.L.; Zhou, S.N. Endophytic fungi from Musa acuminata leaves androots in South China. World Journal of Microbiology \& Biotechnology, London, v.18, p. 69-171, 2002.

3. Cordeiro, Z.J.M.; Matos, A.P.M.; Abreu, K.C.L.M.; Ferreira, D.M.V.F. O Mal-de-Sigatoka da bananeira. Circular Técnica EMPRAPA Mandioca e Fruticultura, Cruz das Almas, n. 4, 2001. 8 p.

4. Cordeiro, Z.J.M.; Matos, A.P.; Filho, P.E.M. Doenças e Métodos de Controle. In: Borges, A.L.; Souza, L.S. O Cultivo da Bana- 
neira. Cruz das Almas, EMBRAPA Mandioca e Fruticultura, 2004. cap. IX, p.146-182.

5. Cordeiro, Z.J.M.; Matos, A. P.; Kimati, H. Doenças da bananeira. In: Kimati, H.; Amorim, L.; Rezende, J.A.M. Bergamin Filho, A.; Camargo, L.E.A.; (Ed.). Manual de fitopatologia. São Paulo: Agronômica Ceres, 2005.v. 2, p. 99-117.

6. Cordeiro, Z.J.M.; Matos, A. P. Expressão da resistência de variedades de banana à sigatoka-amarela. Fitopatologia Brasileira, Brasília, v. 30, n. 5, p. 532-534, 2005.

7. Jenkiss, W. R. A rapid centrifugal flotation technique for extrac- ting nematodes from soil. Plant Disease Reporter, Beltsville, v. 48, p. 692,1964

8. Lopes, E.B.; Albuquerque, I. C. Levantamento fitopatológico de doenças da bananeira com ênfase à Sigatoka Negra (Mycosphaerella fijiensis, MORELET) nos municípios produtores de banana da Paraíba. Circular Técnica da EMEPA. Lagoa Seca, 2004. 12 p.

9. Perez, L.; Papoian, F.; Garcia, R.; Rivero, T. La punta negra de los plátanos (Musa sp: AAB) causada por Deightoniella torulosa. I. Danos y lucha contra La enfermedad. Agrotecnia de Cuba, Cuba, v. 21, p. 101-106, 1989. 